\title{
The Application of Mechanical-Chemical Corrosion Theory in Downhole Tubing $\mathrm{CO}_{2}$ Corrosion Research
}

\author{
Peike Zhu, Wei Yan, Liyu Deng, and Jingen Deng \\ State Key Laboratory of Petroleum Resource and Prospecting, China University of Petroleum, Beijing 102249, China \\ Correspondence should be addressed to Wei Yan; yanwei289@126.com
}

Received 29 September 2014; Revised 29 January 2015; Accepted 30 January 2015

Academic Editor: Zhimin Liu

Copyright (C) 2015 Peike Zhu et al. This is an open access article distributed under the Creative Commons Attribution License, which permits unrestricted use, distribution, and reproduction in any medium, provided the original work is properly cited.

\begin{abstract}
Indoor simulating experiment is a main method for oil field $\mathrm{CO}_{2}$ corrosion research. Experimental parameters are very important for an accurate simulation. Based on the mechanical-chemical corrosion theory, the external load may be possible to accelerate the corrosion rate. However, the influence of $\mathrm{N}_{2}$ pressure on $\mathrm{CO}_{2}$ corrosion during the simulating experiment is negligible. Because the coupon stress induced by additional $\mathrm{N}_{2}$ pressure is very low, therefore, the $\mathrm{N}_{2}$ adding procedure can be cancelled and a more safety working space for researchers will be created. However, it does not mean that mechanical-chemical corrosion influence can be ignored. For downhole tubing, the hoop stress generated from the formation compress or liquid column internal pressure is remarkable; stress effect on corrosion has to be taken into consideration. When pit cavity especially occurred on the internal tubing surface, the stress concentration effect will induce a much higher local stress. Mechanical-chemical corrosion will become significant and more study should be performed on this topic.
\end{abstract}

\section{Introduction}

Downhole casing and tubing $\mathrm{CO}_{2}$ corrosion, a complicated metal degradation process, is a comprehensive topic related to several research areas, such as electrochemical corrosion theories, fluid mechanics, oil and gas separating theory, and downhole string mechanics [1]. Indoor simulating experiment is a main method for $\mathrm{CO}_{2}$ corrosion research. Experiment parameters are very important for accurate simulation. As most researchers have done, $\mathrm{N}_{2}$ gas is added in the container (e.g., autoclave) to a certain formation value in order to simulate the real downhole condition. The complementary pressure, usually very high, is defined by wellbore depth or reservoir pressure. It will result in a higher pressure in the container which is dangerous to the researchers and other people. This paper is trying to investigate if the complementary $\mathrm{N}_{2}$ will have a significant effect on $\mathrm{CO}_{2}$ corrosion results and how much the effect will be.

\section{Theory Basis}

It is considered that the total pressure may have an effect on simulating $\mathrm{CO}_{2}$ corrosion probably because the external pressure will influence the metal's corrosion process and accelerate corrosion rate especially [2-5]. This theory is related to mechanical-chemical phenomenon reported by Gutman. From the perspective of thermodynamic, if the system of identical positive ions is subjected simultaneously to the effect of two external factors-mechanical and electrical, the expression for the reversible potential is as follows:

$$
\widetilde{\bar{\mu}}=\mu_{0}+R T \ln a+n F \varphi+\Delta P V_{m} .
$$

And the decrease of equilibrium electrical potential of the system of positive ions as the result of presence of a mechanical action $(\Delta P)$ is determined by the expression:

$$
\Delta \varphi=-\frac{\Delta P V_{m}}{z F}
$$


where $\mu_{0}$ is the chemical potential of the substance (here refers to metal) in standard state $(a=1) ; R$ is the universal gas constant; $T$ is absolute temperature of a system; $a$ is thermodynamic (ordinary) activity; $\Delta P$ is excess pressure; $V_{m}$ is molar volume of the substance; $n$ is charge transfer valency; $F$ is faraday number; $\varphi$ is electrical potential.

From electrochemical corrosion kinetic view, given the reaction is $\left(M \rightarrow M^{n+}+n e\right)$, the electrochemical activation free energy equals the sum of chemical activation free energy and electrochemical potential. As shown in (3)

$$
\Delta \widetilde{G}_{M}{ }^{X}=\Delta G_{M}^{X}+\beta n F \Delta \Phi
$$

The electrochemical reaction rate is

$$
\begin{aligned}
& \widetilde{v}_{e}=c_{M} \frac{k T}{h} \exp \left(-\frac{\Delta G_{M}^{X}+\beta n F \Delta \Phi}{R T}\right) \\
& \widetilde{v}_{e}=c_{M} \frac{k T}{h} \exp \left(\frac{-\Delta G_{M}^{X}}{R T}\right) \exp \left(-\frac{\beta n F \Delta \Phi}{R T}\right) .
\end{aligned}
$$

Given the reaction rate constant $k_{c}=(k T / h) \exp \left(-\Delta G_{M}^{X} /\right.$ $R T)$, then

$$
\widetilde{v}_{e}=k_{c} c_{M} \exp \left(-\frac{\beta n F \Delta \Phi}{R T}\right)
$$

For a reversible electrochemical reaction,

$$
\begin{aligned}
& \overrightarrow{\widetilde{v}}_{e}=\vec{k}_{c} c_{M} \exp \left(-\frac{\beta n F \Delta \Phi}{R T}\right), \\
& \overleftarrow{\widetilde{v}_{e}}=\overleftarrow{k_{c}} c_{M+} \exp \left(\frac{(1-\beta) n F \Delta \Phi}{R T}\right)
\end{aligned}
$$

where $c_{M}$ is concentration of $M$; $k$ is Boltzmann constant; $T$ is absolute temperature of a system; $h$ is Planck constant; $\Delta \Phi$ is overpotential; $n$ is charge transfer valency; $\beta$ is fraction number (less than 1).

Multiply faraday constant $F$ for (6) and given exchange current $I_{0}=F \overrightarrow{k_{c}} c_{M}=F \overleftarrow{k_{c}} c_{M+}$, then the metal dissolution and deposition current can be expressed as (7) and (8) separately:

$$
\begin{aligned}
& \vec{I}=I_{0} \exp \left(-\frac{\beta n F \Delta \Phi}{R T}\right) \\
& \overleftarrow{I}=I_{0} \exp \left(\frac{(1-\beta) n F \Delta \Phi}{R T}\right) .
\end{aligned}
$$

When external force is applied on a metal which is immersed in an acidic solution, the mechano-electrochemical activation free energy equaled the sum of chemical activation free energy, electrochemical potential, and surface potential elevated by the stress as shown in (9).

As compared to nonstress condition, the external force only changes the free energy of solid state $M$ and has no influence on deposition process (red solid curve):

$$
\Delta \widetilde{\bar{G}}_{M}{ }^{X}=\Delta \widetilde{G}_{M}{ }^{X}-\Delta P V_{m}=\Delta G_{M}^{X}+\beta F \Delta \Phi-\Delta P V_{m} .
$$

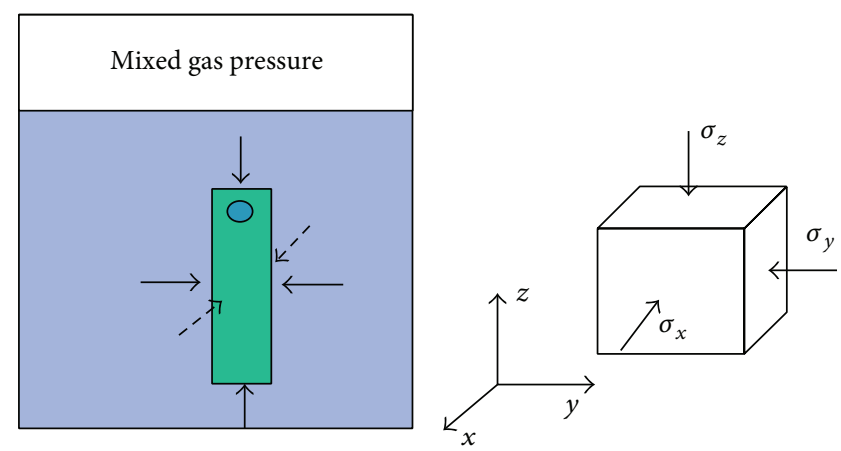

Figure 1: Stress analysis of specimens.

The dissolution current under stress condition is

$$
\widehat{\vec{I}}=I_{0} \exp \left(\frac{-\beta n F \Delta \Phi+\Delta P V_{m}}{R T}\right) .
$$

Stress effect is an influence factor on metal dissolution:

$$
\widehat{\vec{I}}=\vec{I} \times \exp \left(\frac{\Delta P V_{m}}{R T}\right) .
$$

When specimens are immersed into solution sealed with a high-temperature and high-pressure autoclave [6], regardless of the difference of fluid column pressure in height, liquid pressures on specimen from all directions are equal, and unit stress state of specimen is as shown in Figure 1.

It is assumed that the pressure medium in autoclave is pressurized to $20 \mathrm{MPa}$ by $\mathrm{N}_{2}$ during the experiment, and $\sigma_{x}=$ $\sigma_{y}=\sigma_{z}=20 \mathrm{MPa}$ hydrostatic pressure is

$$
\frac{\sigma_{x}+\sigma_{y}+\sigma_{z}}{3}=20 \mathrm{MPa}
$$

And given the temperature is $100^{\circ} \mathrm{C}(373.15 \mathrm{~K})$, molar volume of steel is $7.12 \times 10^{-6} \mathrm{~m}^{3} / \mathrm{mol}$, and gas constant $R$ is $8.314 \mathrm{~J} \cdot \mathrm{mol}^{-1} \cdot \mathrm{K}^{-1}$, according to the discussion in Section 2 (11), the influence coefficient of corrosion rate caused by system pressure is

$$
\exp \frac{V \Delta P}{R T}=\exp \frac{7.12 \times 10^{-6} \times 20 \times 10^{6}}{8.314 \times 373.15}=1.047 \text {. }
$$

Under the system pressure, corrosion rate increases less than $5 \%$. However, the repeated test error rate of corrosion simulation experiment is always between 5\% and $10 \%$, sometimes even higher. Thus it can be considered that pressurization to $20 \mathrm{MPa}$ by nitrogen has little or no influence on the corrosion test result.

\section{Verification Experiments}

A series of experiments were conducted to verify the mechanical-chemical corrosion theory. The materials used in this study are tubing steels, N80, $1 \mathrm{Cr}$, and $3 \mathrm{Cr} 80$. The chemical compositions of the materials are shown in Table 1. The solution used in this study is simulated oil field water. 
TABLE 1: Chemical compositions of N80, 1Cr80, and 3Cr80 (mass fraction, wt\%).

\begin{tabular}{lcccccccc}
\hline Material & $\mathrm{C}$ & $\mathrm{Si}$ & $\mathrm{Mn}$ & $\mathrm{P}$ & $\mathrm{S}$ & $\mathrm{Cr}$ & $\mathrm{Mo}$ & $\mathrm{Ni}$ \\
\hline N80 & 0.24 & 0.22 & 1.19 & 0.013 & 0.004 & 0.036 & 0.021 & 0.028 \\
1Cr80 & 0.20 & 0.27 & 0.42 & 0.0089 & 0.00082 & 1.03 & 0.24 & 0.10 \\
3Cr80 & 0.19 & 0.32 & 0.47 & 0.0089 & 0.00082 & 2.93 & 0.39 & 0.17 \\
\hline
\end{tabular}

TABLE 2: Oil field water ions concentration (mg/L).

\begin{tabular}{llccccc}
\hline $\mathrm{K}^{+} \mathrm{Na}^{+}$ & $\mathrm{Ca}^{2+}$ & $\mathrm{Mg}^{2+}$ & $\mathrm{CL}^{-}$ & $\mathrm{SO}_{4}^{2-}$ & $\mathrm{HCO}_{3}^{-}$ & $\mathrm{CO}_{3}{ }^{2-}$ \\
\hline 8350 & 3885 & 57 & 18975 & 850 & 337 & 0 \\
\hline
\end{tabular}

The $\mathrm{pH}$ value is 6.8 and the ion concentrations are shown in Table $2 . \mathrm{CO}_{2}$ partial pressure is $0.4 \mathrm{MPa}$ and the flow velocity is $1.5 \mathrm{~m} / \mathrm{s}$. Experiments were conducted in three autoclaves at the same time and the $\mathrm{N}_{2}$ pressure filling in three autoclaves is $0 \mathrm{MPa}, 4 \mathrm{MPa}$, and $15 \mathrm{MPa}$, respectively. The equipment for this study is CWYF-1 high-temperature and high-pressure dynamic corrosion autoclave.

The specimens of $50 \mathrm{~mm}$ in length, $10 \mathrm{~mm}$ in width, and $3 \mathrm{~mm}$ in thickness were polished with silicon carbide number 320 and number 600 papers, rinsed with distilled water, degreased in acetone, and then weighed after drying. The specimens were mounted on a specimen holder made of polytetrafluoroethylene (PTFE). The holder was placed in the autoclave filled with corrosive medium, and then the autoclave was closed.

The solution was deoxygenated by pure nitrogen for 2 hours at $45^{\circ} \mathrm{C}$. Then the system was given required partial pressure (the partial pressure of $\mathrm{CO}_{2}$ is $0.4 \mathrm{MPa}$, maintenance purging $\mathrm{CO}_{2}$ for 1 hour until solution in the autoclave gets saturated and controlled the design pressure by nitrogen) and temperature $\left(90^{\circ} \mathrm{C}\right)$. After 72 hours, the specimen surfaces were washed with distilled water and the corrosion products were pickled in $10 \%$ hydrochloric acid solution to get removed and the solution contained an inhibitor to protect the base. Then the specimens were rinsed with distilled water, degreased in acetone, and dried, after that the specimens were photographed to record the corrosion status. Finally, the residual masses of the specimens were weighed on an electronic balance (accuracy $0.1 \mathrm{mg}$ ) and the average corrosion rate was calculated according to NACE RP07752005.

As shown in Table 3, under the three pressure conditions, there is little difference in the corrosion of the same material. Severe pitting corrosion appeared on the N80 specimens but $1 \mathrm{Cr} 80$ and $3 \mathrm{Cr} 80$ suffered general corrosion. As shown in Figure 2, the corrosion rates of N80 under three pressure conditions are basically consistent, $1 \mathrm{Cr} 80$ and 3Cr80 are similar to N80 and the corrosion rate did not increase with system pressure. Thus it can be seen that when the $\mathrm{CO}_{2}$ partial pressure is constant (i.e., the content of $\mathrm{CO}_{2}$ in the solution is constant), the system pressure (i.e., hydrostatic pressure) has little impact on the corrosion rate and corrosion morphology.

According to the results of indoor simulation experiments and mechanical-chemical corrosion theory, additional $\mathrm{N}_{2}$ did not have obvious impact on the coupons surface in the same material and the general corrosion rates are much closer

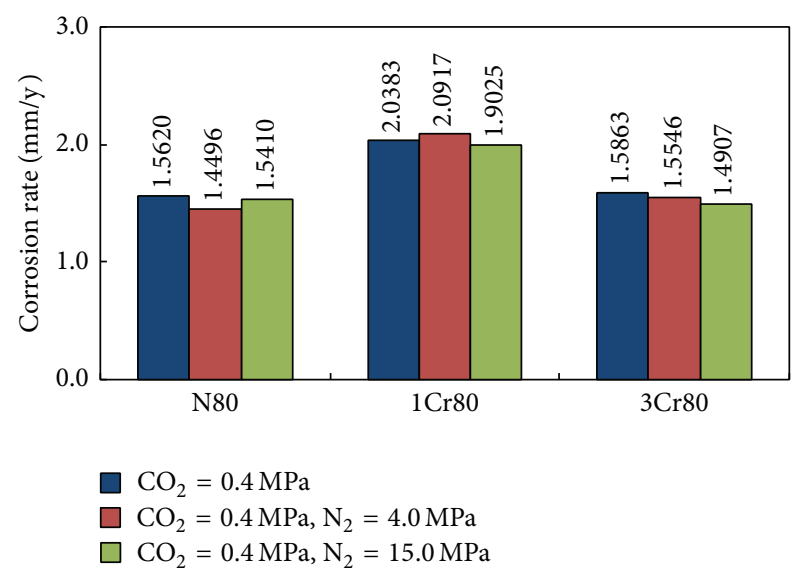

FiguRE 2: Corrosion rates contrast under different total pressures.

for each material. Thus, adding $\mathrm{N}_{2}$ can be omitted during the simulation experiment. Without adding high $\mathrm{N}_{2}$ pressure, the test result is still reliable enough. Skip this process can reduce the experiment cost and make it more efficient. What is more important is that skipping this high-pressure process can avoid potential security threats to the researchers.

\section{Stress Analysis in Anticorrosion Design for Downhole String}

Equation (13) can be regarded as an influence coefficient of corrosion process. Under different temperature, the relationship between influence coefficient and stress is shown in Figure 3.

Figure 3 demonstrates that stress influence coefficient of corrosion is very small under the low stress conditions; when stress is greater than $100 \mathrm{MPa}$, the impact of stress on corrosion is gradually increased and becomes nonignorable. In addition, the promotion of the stress in low temperature corrosion is greater than that in high-temperature corrosion. This needs to be stressed that corrosion rate is different from coefficient of corrosion, but the corrosion has positive correlation with coefficient of corrosion and a higher coefficient will induce a higher corrosion rate.

Under the internal fluid pressure, formation (or cement) external extrusion pressure, axial force, and bending, the wall stress of downhole string often can reach a much higher 
TABLE 3: Appearance of specimen and average corrosion rate.

\begin{tabular}{|c|c|c|c|c|}
\hline Material & Photos of specimen & Corrosion & System pressure & $\begin{array}{c}\text { Corrosion rate } \\
\mathrm{mm} / \mathrm{a}\end{array}$ \\
\hline \multirow{3}{*}{ N80 } & & Pitting & $0.4 \mathrm{MPa} / 0 \mathrm{MPa}$ & 1.5620 \\
\hline & & Pitting & $0.4 \mathrm{MPa} / 4 \mathrm{MPa}$ & 1.4496 \\
\hline & & Pitting & $0.4 \mathrm{MPa} / 15 \mathrm{MPa}$ & 1.5410 \\
\hline \multirow{3}{*}{$1 \mathrm{Cr}$} & & $\begin{array}{c}\text { General } \\
\text { corrosion }\end{array}$ & $0.4 \mathrm{MPa} / 0 \mathrm{MPa}$ & 2.0383 \\
\hline & & $\begin{array}{l}\text { General } \\
\text { corrosion }\end{array}$ & $0.4 \mathrm{MPa} / 4 \mathrm{MPa}$ & 2.0917 \\
\hline & & $\begin{array}{l}\text { General } \\
\text { corrosion }\end{array}$ & $0.4 \mathrm{MPa} / 15 \mathrm{MPa}$ & 1.9025 \\
\hline \multirow{3}{*}{$3 \mathrm{Cr}$} & & $\begin{array}{c}\text { General } \\
\text { corrosion }\end{array}$ & $0.4 \mathrm{MPa} / 0 \mathrm{MPa}$ & 1.5863 \\
\hline & & $\begin{array}{l}\text { General } \\
\text { corrosion }\end{array}$ & $0.4 \mathrm{MPa} / 4 \mathrm{MPa}$ & 1.5546 \\
\hline & & $\begin{array}{c}\text { General } \\
\text { corrosion }\end{array}$ & $0.4 \mathrm{MPa} / 15 \mathrm{MPa}$ & 1.4907 \\
\hline
\end{tabular}

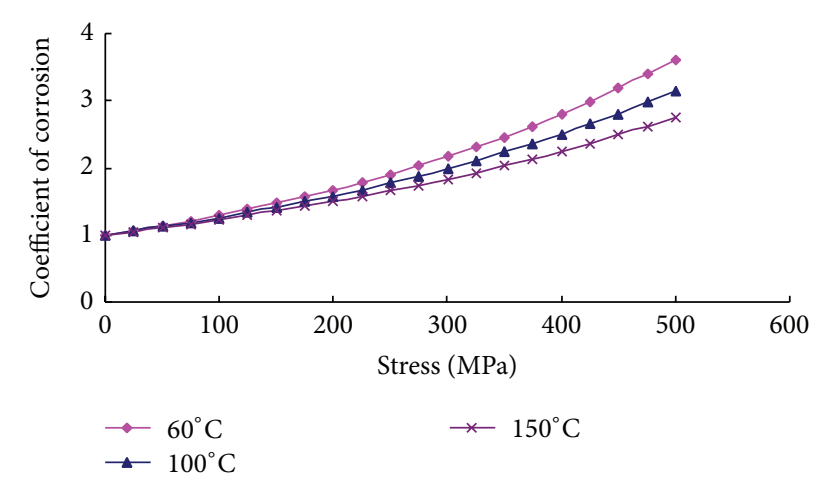

FIGURE 3: The relationship between corrosion coefficient and average normal stress.

stress level (greater than $100 \mathrm{Mpa}$ ). In the process of downhole tubing anti-corrosion design, the hoop stress on the casing wall under the internal pressure has obvious promoting effect on corrosion rate. For the larger diameter-thickness ratio pipe, circumferential stress on the wall under internal pressure can be calculated by [7]

$$
\sigma=\frac{\mathrm{pr}_{o}}{t}
$$

It is assumed that casing outer diameter is $9-5 / 8^{\prime \prime}$, wall thickness is $11.99 \mathrm{~mm}$, and inner pressure is $20 \mathrm{MPa}$. The wall stress calculated by above equation is $205 \mathrm{MPa}$ (elastic modulus is $208 \mathrm{GPa}$ and Poisson's ratio is 0.28 ).

According to the curve in Figure 3, when the stress is $200 \mathrm{MPa}$, influence coefficient of corrosion rate is about 1.5 which will have great influence on the corrosion.

Another more serious situation is stress concentration around pits in internal surface of downhole tubing. The finite element model of two spherical pits is shown in Figure 4.

Model parameters are as follows: outer diameter: $244.5 \mathrm{~mm}\left(9-5 / 8^{\prime \prime}\right)$; wall thickness: $11.99 \mathrm{~mm}$; casing grade: N80; elastic modulus: $208 \mathrm{Gpa}$; Poisson's ratio: 0.28 ; hemisphere pits diameter: $8.0 \mathrm{~mm}(R=4.0 \mathrm{~mm})$; pit cavity depth: $4.0 \mathrm{~mm}$. 

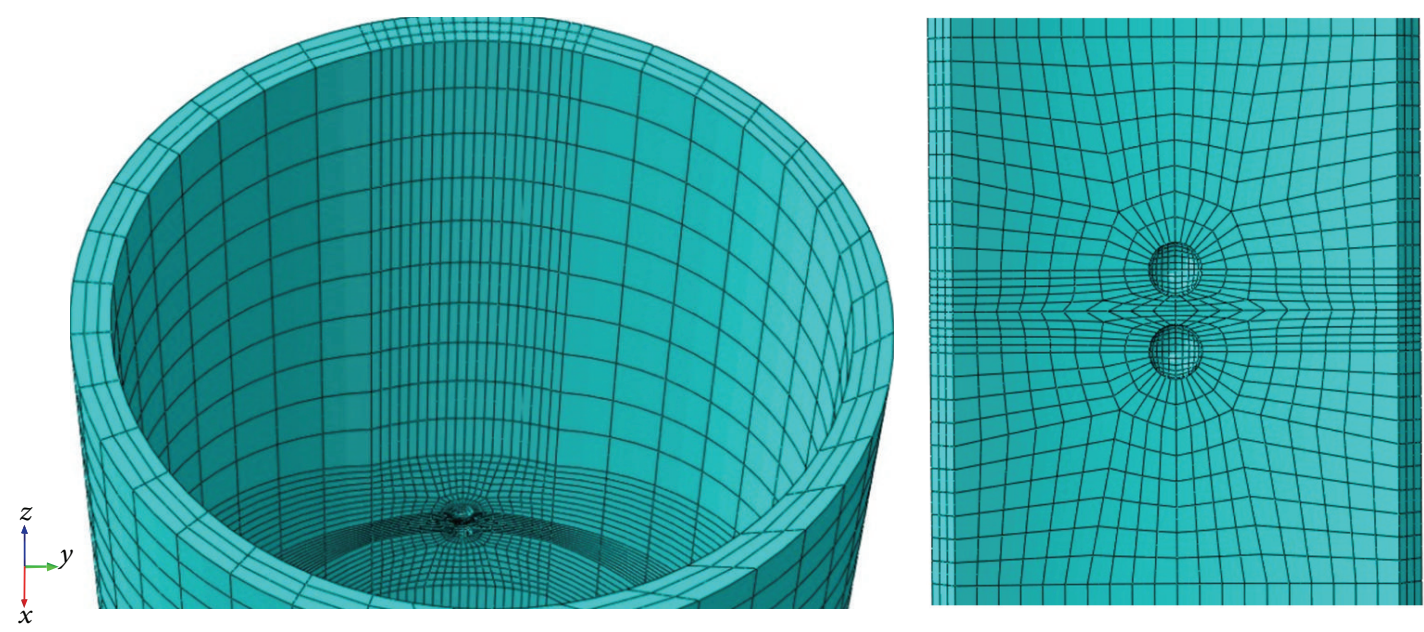

FIGURE 4: Finite element models of two spherical pits in casing internal surface.
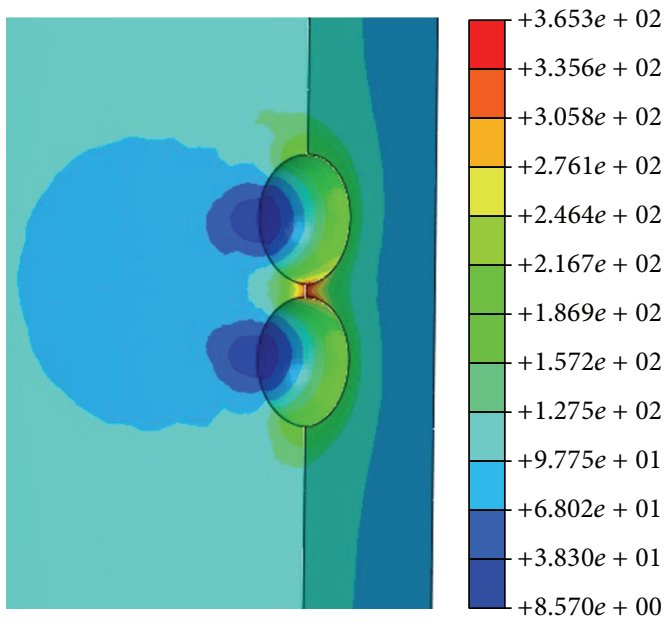

Figure 5: Cross section stress distribution of double cavities $(L / R=$ 2.2).

When the ratios of $L / R$ ( $L$ is the distance between two hemisphere centers) are equal to 2.2 and 1.0 , respectively (center distance between the two pits and radius), and internal pressure is $10 \mathrm{MPa}$, the stress distribution around the pits is shown in Figures 5 and 6.

Tensile stress appears at the intersecting line of the concave of pit and $X-Z$ plane and the maximum stress is in the double pits intersection. Figures 6 and 7 are the profiles along the axis of casing and through the center of pit.

When $L / R=2.2$ (Figure 5), the stress concentration factor is $365 \mathrm{MPa} / 100 \mathrm{MPa}=3.65$; when $L / R=1.0$ (Figure 6), the stress concentration factor is $292 \mathrm{MPa} / 100 \mathrm{MPa}=2.92$.

When $L / R=2.2$, as shown in Figure 7, stress at the outer edge of pit is $209 \mathrm{MPa}$, stress at the inner edge of pit is $365 \mathrm{MPa}$, which is maximum, bottom stress is $197 \mathrm{MPa}$, the distance between the inner edges of the two pits is $0.8 \mathrm{~mm}$, and midpoint stress at the inner edge of double pits is $325 \mathrm{MPa}$. When $L / R=1.0$, as shown in Figure 8, the stress
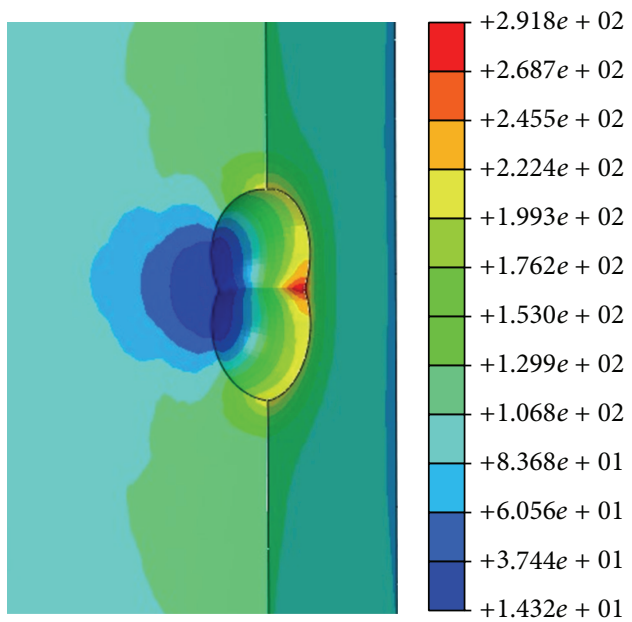

FIgURE 6: Cross section stress distribution of single cavity $(L / R=$ $1.0)$.

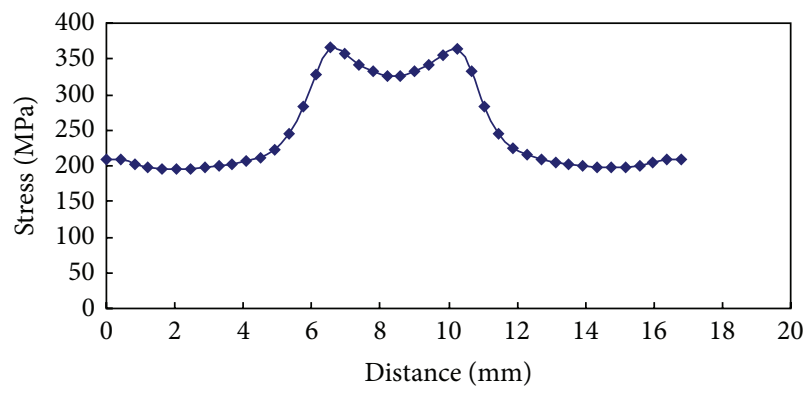

FIgURE 7: The stress of node on the intersecting lines between $X-Z$ plane and cavity, $L / R=2.2$.

at the outer edge of pit is $214 \mathrm{MPa}$, stress at the inner edge of pit is $292 \mathrm{MPa}$, which is maximum, bottom stress is $203 \mathrm{MPa}$, two-pit-intersect, and the maximum stress at the intersection is $292 \mathrm{MPa}$. 


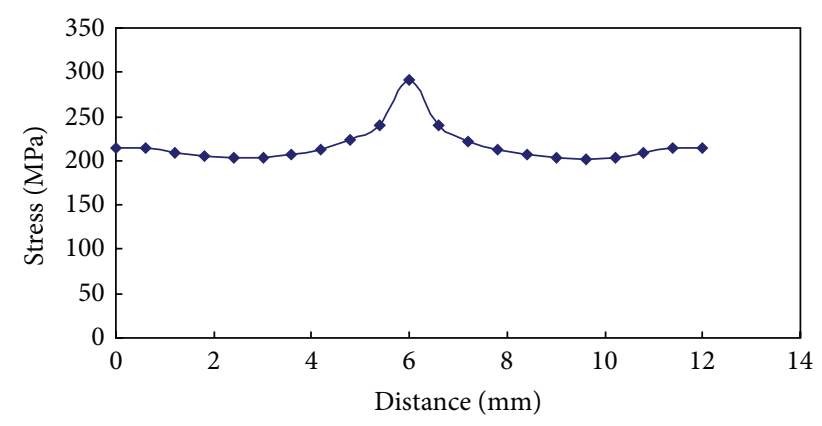

FIgURE 8: The stress of node on the intersecting lines between $X-Z$ plane and cavity, $L / R=1.0$.

According to mechano-chemical corrosion theory, stress influence coefficient can reach 2.5. Therefore, when selecting anti-corrosion materials for downhole string and evaluating service life of the tubing string for the corrosive gas fields, it is necessary to consider wall stress influence on electrochemical corrosion.

\section{Conclusion}

(1) If the stress is not very high (less than $50 \mathrm{MPa}$ ), the influence of stress on corrosion process is negligible.

(2) The influence of system pressure on corrosion rate can be ignored and the procedure of adding inert gas (e.g, Nitrogen) pressure can be skipped. In this way, the experimental efficiency will be increased and the security threats from the high pressure autoclave can be avoided.

(3) Downhole tubing hoop stress generated due to the formation compress or liquid column pressure is remarkable, therefore, stress effect has to be taken into consideration. Especially, when pit corrosion occurred on the internal tubing surface, the stress concentration effect will raise the local stress to a much higher value.

\section{Conflict of Interests}

The authors declare that there is no conflict of interests regarding the publication of this paper.

\section{Acknowledgment}

The research work was supported by China University of petroleum (Beijing) Scientific Research Fund Project (YJRC2013-19).

\section{References}

[1] W. Yan, J. Deng, X. Dong et al., "Investigation of calculation method of $\mathrm{CO}_{2}$ partial pressure in oil and gas well," Drilling \& Production Technology, vol. 34, no. 5, pp. 19-22, 2011 (Chinese).

[2] E. M. Gutman, Mechanochemistry of Materials, Cambridge International Science, 1998.
[3] T. G. Movchan, N. E. Esipova, P. V. Eryukin, N. B. Uriev, and A. I. Rusanov, "Mechanochemical effects in processes of corrosion of metals," Russian Journal of General Chemistry, vol. 75, no. 11, pp. 1681-1686, 2005.

[4] X. F. Liu, J. Zhan, and Q. J. Liu, "The influence of tensile stress on electrochemical noise from aluminum alloy in chloride media," Corrosion Science, vol. 51, no. 6, pp. 1460-1466, 2009.

[5] S. Rao, L. Zhu, D. Li, Z. Zhang, and Q. Zhong, "Effects of mechanochemistry to the pitting behaviour of LY12CZ aluminum alloy," Journal of the Chinese Society of Corrosion and Protection, vol. 27, no. 4, pp. 228-232, 2007.

[6] W. Yan and J. Deng, "Investigation of mechanochemical corrosion of downhole tubing and casing," China Offshore Oil and Gas, vol. 26, no. 1-2, pp. 87-91, 2014.

[7] H. Liu, Material Mechanics, Higher Education Press, Beijing, China, 2006. 

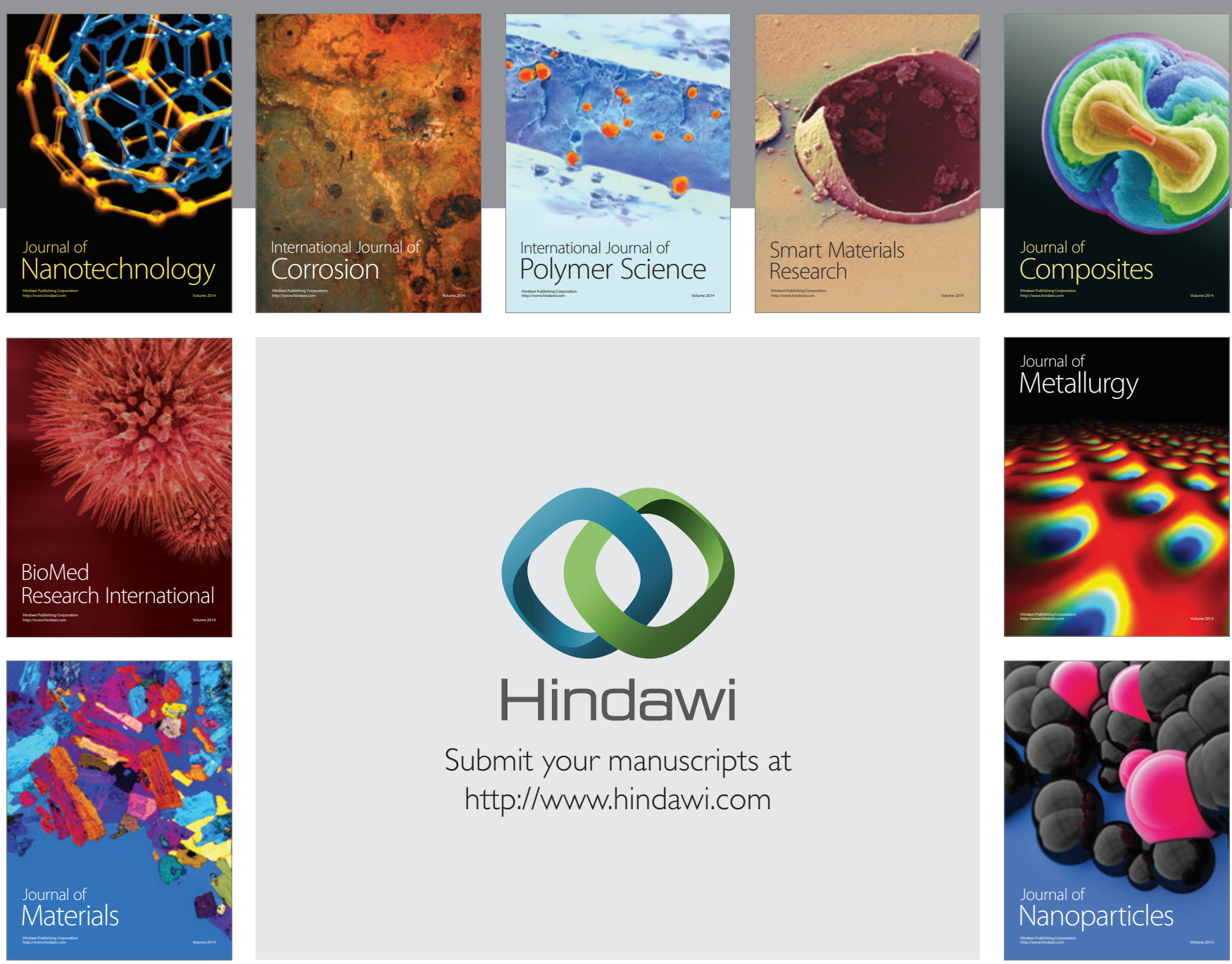

Submit your manuscripts at http://www.hindawi.com
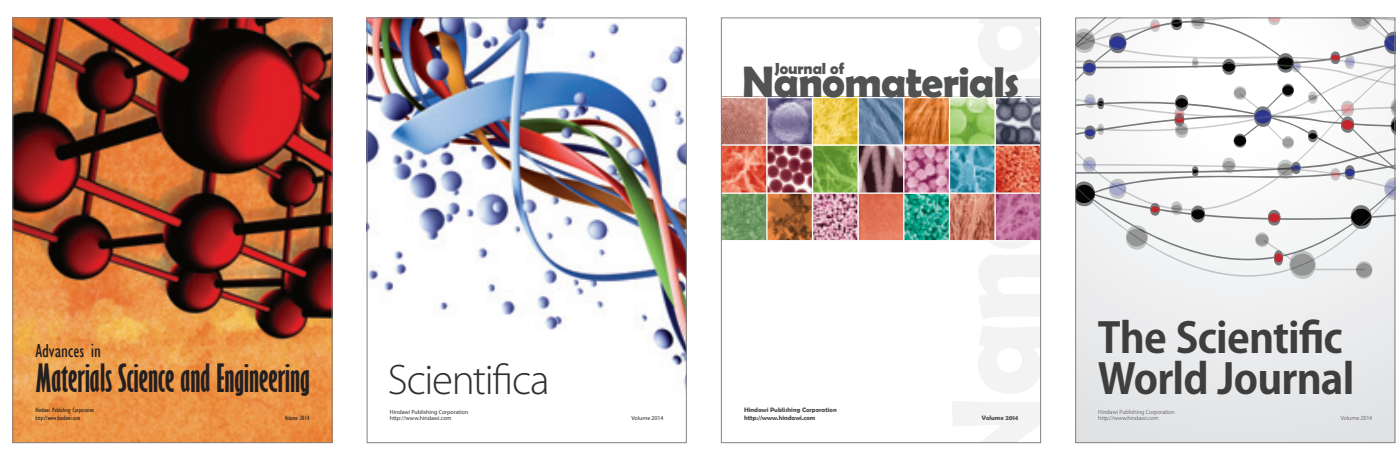

\section{The Scientific World Journal}
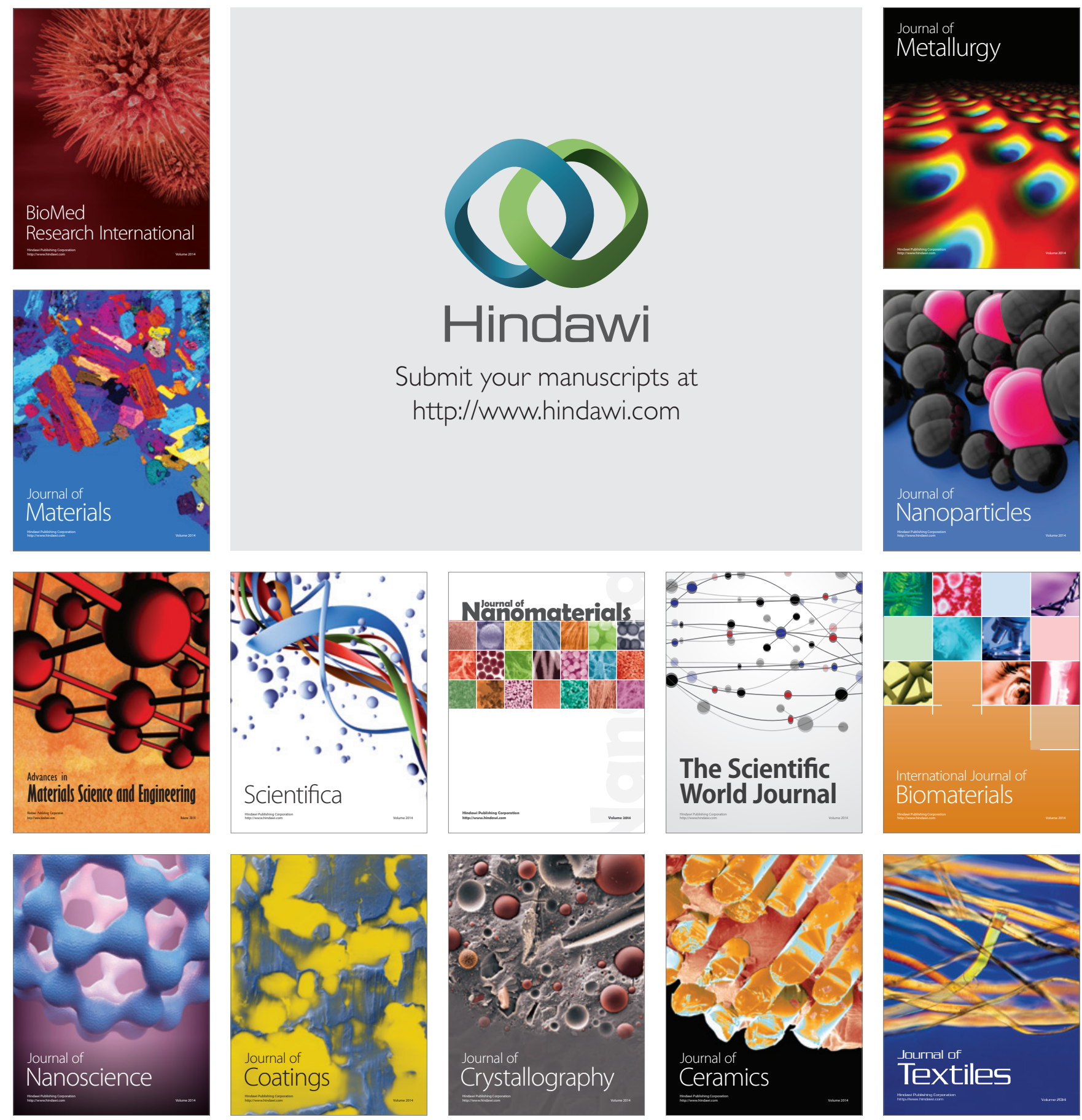